\title{
COMPARISON OF USER PERFORMANCE WITH INTERACTIVE AND STATIC 3D VISUALIZATION - PILOT STUDY
}

\author{
L. Herman ${ }^{\mathrm{a}}$ *, Z. Stachoñ ${ }^{\mathrm{a}}$ \\ ${ }^{a}$ Department of Geography, Faculty of Science, Masaryk University, Kotlářská 2, 61137 Brno, Czech Republic - \\ herman.lu@mail.muni.cz,14463@sci.muni.cz \\ * corresponding author
}

ThS16: Perceptual and cognitive experiments with imagery and 3D models

KEY WORDS: 3D visualization, exploratory study, interactive visualization, perspective view, usability, user performance.

\begin{abstract}
:
Interactive 3D visualizations of spatial data are currently available and popular through various applications such as Google Earth, ArcScene, etc. Several scientific studies have focused on user performance with 3D visualization, but static perspective views are used as stimuli in most of the studies. The main objective of this paper is to try to identify potential differences in user performance with static perspective views and interactive visualizations. This research is an exploratory study. An experiment was designed as a between-subject study and a customized testing tool based on open web technologies was used for the experiment. The testing set consists of an initial questionnaire, a training task and four experimental tasks. Selection of the highest point and determination of visibility from the top of a mountain were used as the experimental tasks. Speed and accuracy of each task performance of participants were recorded. The movement and actions in the virtual environment were also recorded within the interactive variant. The results show that participants deal with the tasks faster when using static visualization. The average error rate was also higher in the static variant. The findings from this pilot study will be used for further testing, especially for formulating of hypotheses and designing of subsequent experiments.
\end{abstract}

\section{INTRODUCTION}

Applications like Google Earth and Virtual Earth have generated considerable expansion of the third dimension in the cartographical and geoinformatics domain. Interactive 3D visualization of spatial data is nowadays used for many applications and for many issues. As the use of 3D visualization of spatial data in areas of emergency and crisis management, noise mapping, urban planning, geography teaching or virtual tourism is growing (Lin et al., 2015; Hirmas et al., 2014; Herman and Reznik, 2013; Reznik et al., 2013; Kovalcik et al., 2012; Konecny, 2011; Stanek et al., 2010), the usability of 3D visualization are discussed within the field of human factors more often. Some authors, e.g. Vozenilek (2005), argue that 3D visualization is capable to present a large amount of complex information to wider audiences, including those with little or no cartographic or GIS literacy. The pilot study presented in this paper aims to verify the above mentioned statement.

Shepherd (2008) describes the general benefits of the 3D visualization of spatial data. The main advantages are the existence of more space for displaying additional data variables, resolving of issues related to hidden symbols, and access to a more familiar view of space. On the other hand, Shepherd (2008) and Jobst and Germanchis (2007) pointed out possible issues that may arise during $3 \mathrm{D}$ visualization. These include the occlusion of objects in a 3D scene, perspective distortion, the existence of variable scales within a single view, and incomparable geometries of objects. In addition, there are some solutions for the disadvantages and the most mentioned is the interactive movement in 3D scene. In our opinion, interactive $3 \mathrm{D}$ visualization, which allows virtual movement and navigation, is dissimilar to static perspective views on 3D data, which the users use; stimulate entirely different working strategies and cognitive processes.
This paper aims to identify the differences in user performance and static perspective views and interactive $3 \mathrm{D}$ visualization. Unique experimental tools based on web technologies were used for this test. At first, we analysed speed and accuracy of users performance. Furthermore, movement and interactions in virtual environment were recorded within the interactive visualization.

\section{RELATED WORK}

Several scientific studies have focused on user performance with $3 \mathrm{D}$ visualization, mostly using the static perspective views as stimuli. The usability of interactive $3 \mathrm{D}$ visualization is an issue that has not been extensively analysed and relatively too little is still known about how interactive 3D visualizations may be used effectively.

Probably the first research focused on usability of 3D visualizations was performed by Kraak (1988). Subjective preferences of 3D map users were investigated by Petrovic and Masera (2004). Haeberling (2003) evaluated visual variables used in the 3D visualizations (rotation angle of camera, camera distance, lighting direction, and haze). Savage et al. (2004) searched possible advantages of using 3D perspective view compared to traditional 2D topographic maps. Schobesberger and Patterson (2007) compared the differences between 2D and 3D maps of Zion National Park in Utah (US).

Bleisch and Dykes (2008) studied differences of suitability of 2D and 3D maps for planning mountain hikes. Niedomysl et al. (2013) compared static maps (2D and 3D) in terms of their use in a geographic education process. Rautenbach et al. (2014) evaluated and compared 2D maps, 3D non-photorealistic 
landscapes and 3D realistic city models for urban planning. Torres et al (2013) examines satisfaction with different technologies for real 3D visualization (anaglyph, autostereo and shutter glasses). Zanola et al. (2009) concentrate on stereoscopic visualization and evaluate suitability of abstract and realistic styles of 3D models for urban planning. In addition, several studies performed with the use $3 \mathrm{D}$ visualizations that used eyetracking for the research methodology were published, e.g. Popelka and Brychtova (2013), and Popelka and Dolezelova (2015).

An important fact is that all the above-mentioned articles used only static perspective views as the stimuli. Not many experiments that took place in an interactive $3 \mathrm{D}$ virtual environment have been published. One of those studies is the work of Wilkening and Fabrikant (2014). They used Google Earth application and the participants dealt with practical tasks (e.g. finding the highest point along a given path). They monitored the proportion of applied movement types - zooming, panning, tilting and rotating. However, this article neither specified how the acquisition and storage of different types of movement was made, nor which technology was used for such purpose.

Bleisch et al. (2008) assessed potential combination of 3D visualization environment and abstract data, when comparing differences between reading the height of $2 \mathrm{D}$ bar charts and reading bar charts placed in 3D environment. Speed and correctness were measured, although the information about the movement was neither recorded nor evaluated, despite the fact that a 3D interactive environment was used. The works dedicated to the analysis of interactive movement include Abend et al. (2012) and others. This work focuses on processing of videos captured during user browsing in Google Earth.

In all the above mentioned studies had a similar feature - when the interaction with 3D virtual space was possible, it was neither recorded nor analysed. The only exception is the work of Wilkening and Fabrikant (2014). This situation motivated the authors to produce this paper. Therefore, the main objective of this paper is to try to identify differences in user performance with static perspective views and interactive $3 \mathrm{D}$ visualizations.

\section{EXPLORATORY STUDY}

Dealing with the lack of studies and methodological approaches, we decided for the exploratory approach. The main focus was laid on gaining insights and experience for further performance of $3 \mathrm{D}$ visualization research.

\subsection{Design}

The experiment was designed as a between-subject study, and the participants were randomly divided into two groups. One group worked with interactive $3 \mathrm{D}$ visualizations and the other one with static perspective views, which were identical to the first views of the interactive variant. The testing was conducted in September 2015.

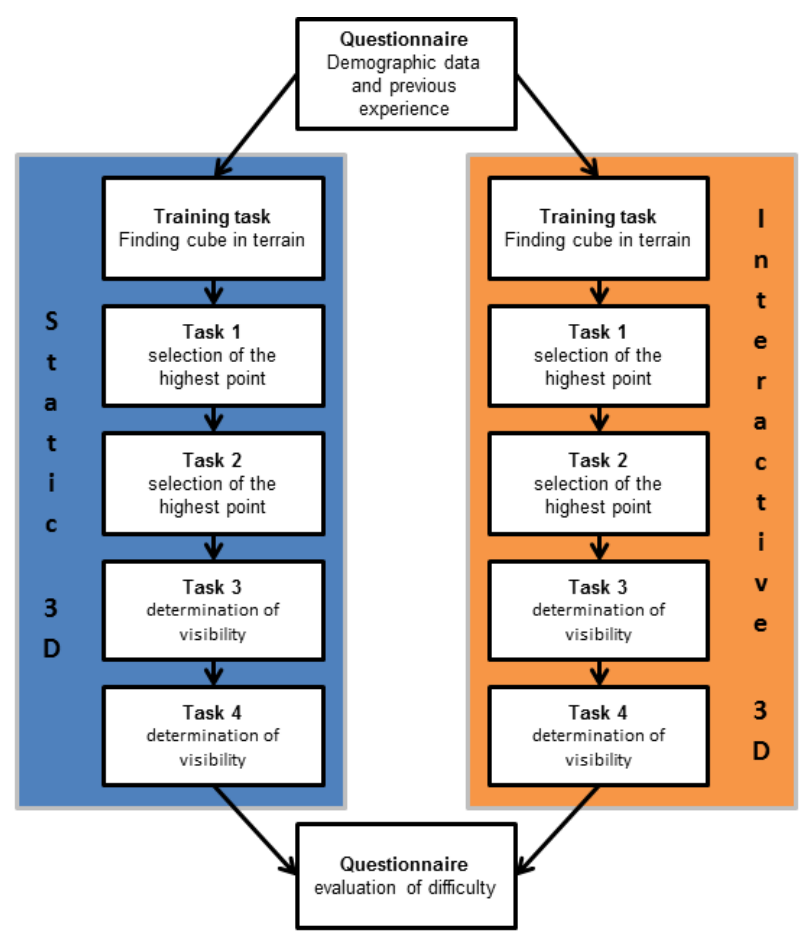

Fig. 1. Design of the experiment

\subsection{Methodology and tools}

Due to the lack of tools for usability testing of 3D visualization, an experimental tool was designed and implemented. This testing tool is based on open web technologies: HTML (HyperText Markup Language), PHP (Hypertext Preprocessor), JavaScript and JavaScript library for 3D rendering X3DOM. X3DOM library was chosen for the implementation for its wide support among commonly used Web browsers, as well as for the availability of software to create stimuli and accessibility of the documentation. X3DOM uses the data structure of X3D (eXtensible 3D) format and is built on HTML5 and JavaScript library WebGL. Principles, advantages and capabilities of X3DOM are described for example by Behr et al (2009), and Herman and Řezník (2015).

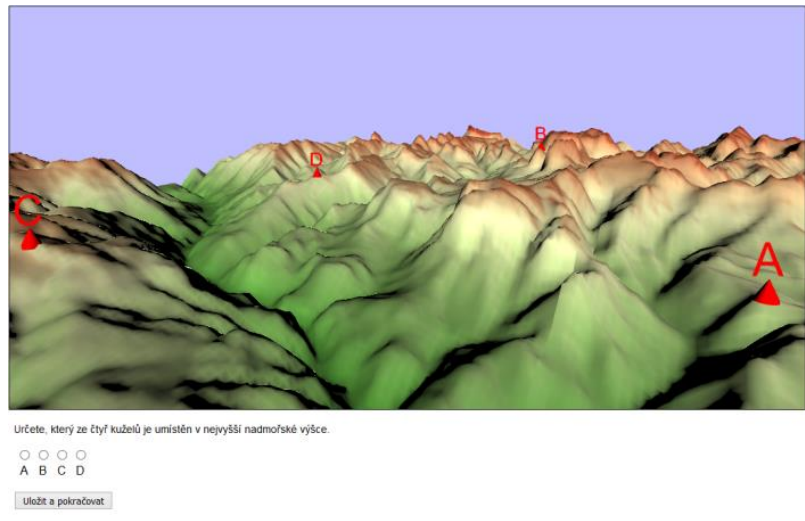

Fig. 2. Testing tool interface (task 1, interactive variant)

Speed and accuracy of each task performance of a particular participant were recorded by the testing tool. The movement and actions in a virtual environment were also recorded in detail within the interactive variant. Functions called evt.position and evt.orientation were used to obtain these data (see X3DOM, 2016). Usual JavaScript events, such as onmousedown, are used to detect user interaction and used types of movement. The 
input features, e.g. buttons, checkboxes, radio buttons, are implemented with the use of conventional HTML elements.

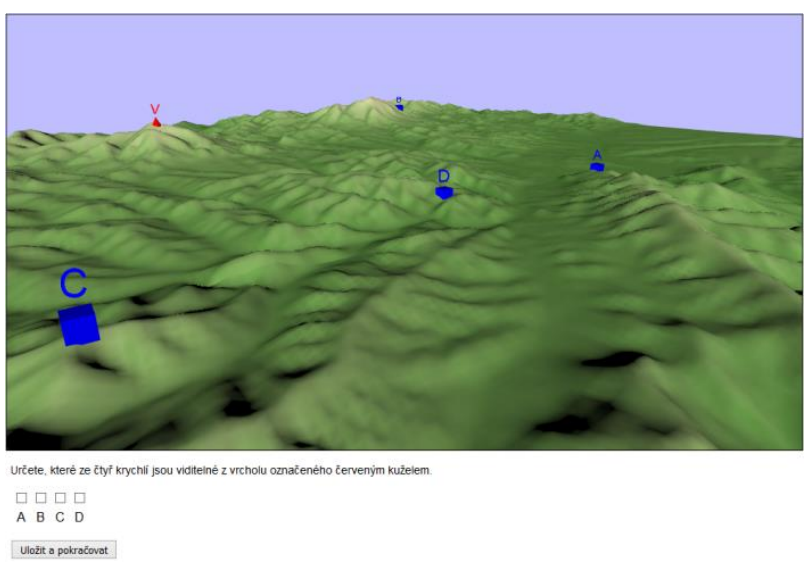

Fig. 3. Determination of visibility (task 3 , interactive variant)

\subsection{Tasks and stimuli}

The testing set started with an initial questionnaire, followed by a training task, continued with four experimental tasks and concluded with a final questionnaire (see Fig. 1). The first and the second tasks focused on finding the highest one out of four points. The third and fourth tasks focused on the determination of visibility of four points from the top of a particular mountain.

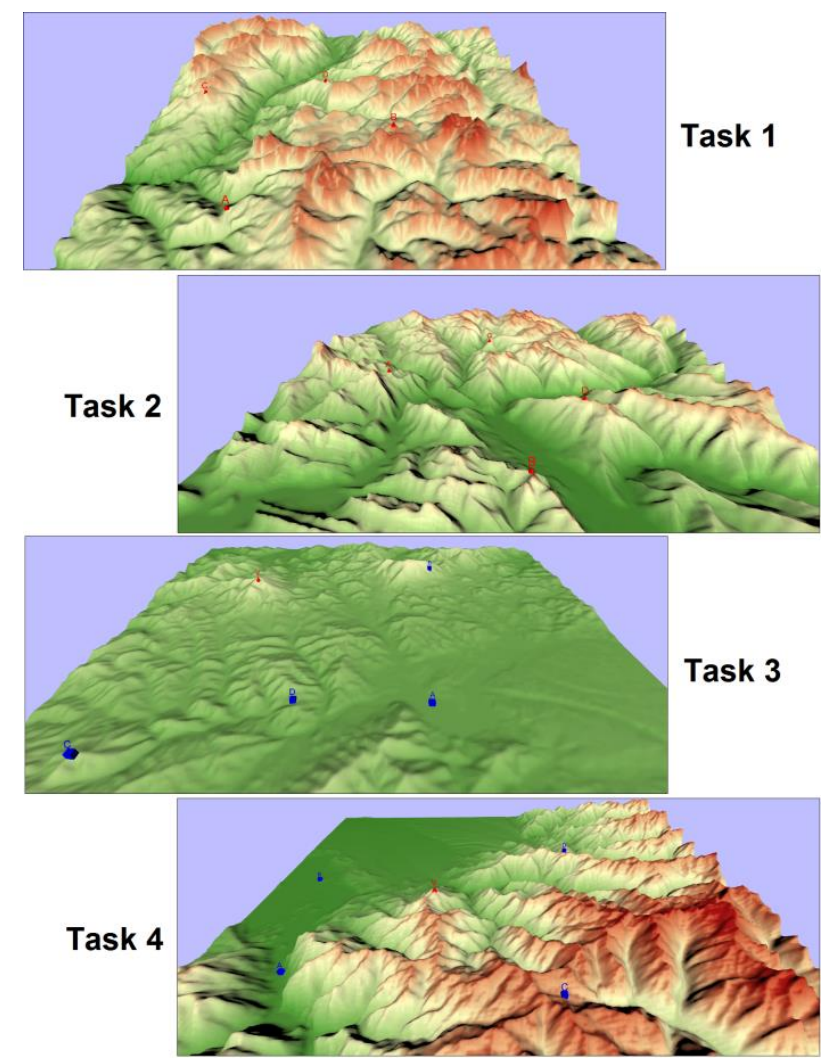

Fig. 4. Starting views similar to perspective views used in static variant

Digital terrain models represented the main part of the stimuli used for the experiment (see Fig. 2, 3 and 4). Terrain models from five different (hilly or mountainous) areas in Europe from SRTM (Shuttle Radar Topography Mission) were used. These data were processed in the ArcGIS (v. 10.2.) software. Raster terrain models were transferred to regularly arranged points which were transformed into TIN (Triangulated Irregular Network) models created from the points (in the Universal Transverse Mercator (UTM) coordinate system). These TINs were converted into raster terrain models and then clipped to a smaller size. They were visualised in ArcScene, their real heights were doubled, and the colour scheme was set. Then they were exported to VRML (Virtual Reality Modelling Language) files and converted into an X3D.

The stimuli in the static variant were perspective views, which were identical to the starting views from the interactive variant of the experiment. These perspective views were generated from X3DOM API function getScreenshot().

The type of movement, which is called 'examine', was chosen for the interactive variant. Examine consists of three specific motions: pan (performed by middle mouse button), zoom (right mouse button) and rotate (left mouse button). The participants tried all the individual motions during the training tasks in the interactive part.

\subsection{Participants}

The group of participants included 22 volunteers - participants in the action "Researchers Night". There were 17 males and 5 females with an average age of 23.5 years $(8$ males and 3 females with an average age of 23 years for the interactive variant; 9 males and 2 females with an average age of 24 years for the static variant). All participants had some previous experience with computerized 3D visualization applications, but none of them was an expert.

The participants were randomly divided into two groups with respect to an equal proportion of males and females. There were equivalent experimental conditions for both static and interactive 3D visualizations including all environmental issues, such as noise, light conditions, etc. All participants agreed with the procedure and participated voluntarily, with an opportunity to withdraw from testing any time. All participants were rewarded with small gifts after the end of the testing. They were initially instructed that accuracy of answers is more important than speed, and they were also informed that their performance time is measured.

\section{RESULTS}

The duration of tasks (speed of users' performance), correctness of answers, errors and subjective evaluation of the difficulty of individual tasks were analysed. The actions in a virtual environment were also recorded a analysed in the interactive variant.

\subsection{Correctness}

The average correctness was higher in the static variant. It seems that interactive visualization has no benefits from this point of view (see Fig. 5). The greatest difference of results was found for two evaluated types of 3D visualization in the fourth task. These results may be influenced by the nature of the used terrain, by the initial position of the virtual camera and thus the corresponding static perspective view. 


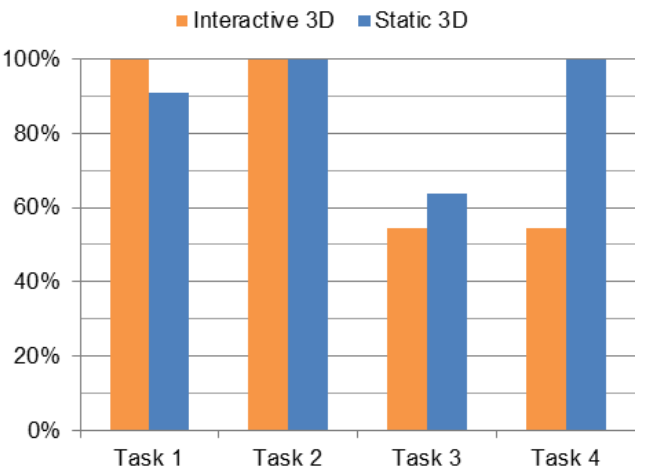

Fig. 5. Average correctness in percentage

The correct answers in Fig. 5 are considered those which are entirely correct. They are listed in Tab. 1.

\subsection{Errors}

We can also look in more detail at the errors made by the participants. As mentioned above, there is a difference between the first and second task (with one possible answer) and the third and fourth task, where the user was choosing among four options (A - D). The interface of third task is shown in Fig. 3. We can use the correctness and errors rate only to compare the static and interactive variants of $3 \mathrm{D}$ visualization, but not to compare the performance among different tasks. Both correct and incorrect answers are summed up in Tab. 1 .

\begin{tabular}{|c|c|c|c|}
\hline & \multirow{2}{*}{$\begin{array}{c}\text { Correct } \\
\text { answer }\end{array}$} & \multicolumn{2}{|c|}{ Wrong or incomplete answers } \\
\cline { 3 - 4 } & Interactive 3D & Static 3D \\
\hline Task 1 & B & - & D \\
\hline Task 2 & D & - & - \\
\hline & & A & A \\
Task 3 & A, C & $\begin{array}{c}\text { C (3x) } \\
\text { A, C, D }\end{array}$ & $\begin{array}{c}\text { A, B, C (2x) } \\
\text { A, C, D }\end{array}$ \\
\hline & & $\begin{array}{c}\text { B } \\
\text { D (2x) } \\
\text { Task 4 D } \\
\text { C, D }\end{array}$ & \\
\hline
\end{tabular}

Tab. 1. Summary of correct and wrong answers

Regarding the tasks related to determination of visibility, the majority of errors in the static version were omission errors. Users selected more than two right answers. Commission errors (in this case only one selected answer) are more common in the interactive version. This may indicate different task-solving strategies between both variants of $3 \mathrm{D}$ visualization.

\subsection{Duration of users performances}

The participants worked on three tasks (first, second and fourth) faster when using the static visualization. The only exception is the third task, where the average speed of the task performance is lower for the interactive visualization (see Fig. 6). These results can be interpreted in such way that the solution of the task in slightly rugged terrain requires relatively less time to find the answers. However, this task showed the lowest correctness of answers, which is the lowest in both variants of visualization. A comparison of correctness and duration of the task performance indicates that the third and fourth tasks were more demanding for the majority of participants (lower correctness, longer duration of task performance).

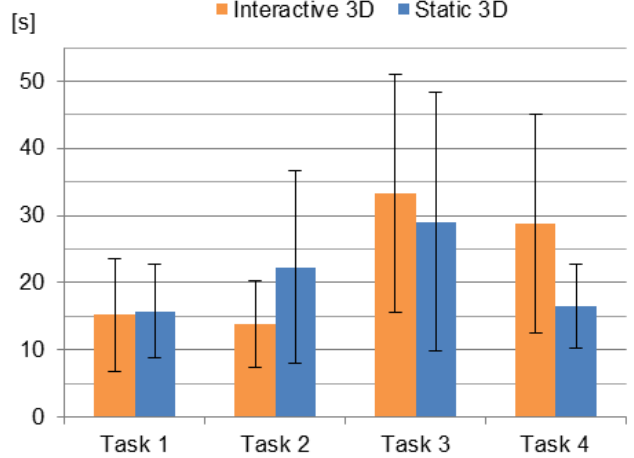

Fig. 6. Average speeds (lengths) and standard deviations of task performance

The values of standard deviations indicate (shown in Fig. 6) that the differences between users are clearer than differences between two types of visualization. This fact may be related to different experience of individual participants regarding their work with a virtual 3D environment. The standard deviations are more variable mainly for less experienced users.

\subsection{Analysis of interactive movement}

We also studied the actions used for interaction with different types of terrain in the interactive variant of 3D visualization. We looked at the proportion of individual types of movement during the tasks performance particularly regarding the user strategies. The average lengths of using particular types of movement (zoom, pan, rotation) and length of time when the users did not interact with 3D scene is shown in Fig. 7. Regarding the nature of stimuli and tasks, it is obvious that the users most frequently rotated with terrain. In general, panning and zooming are used only marginally although participants in the interactive variant had to try all three types of movement in their training task.

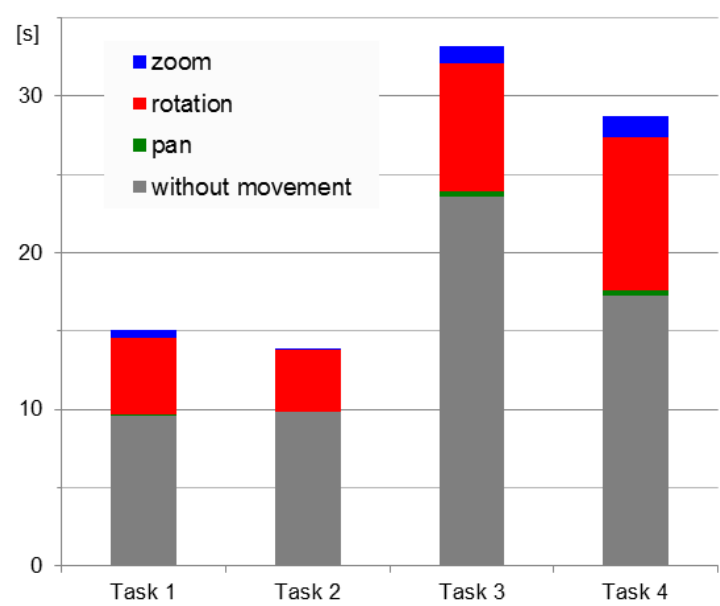

Fig. 7. Average duration of use of individual types of movement

The differences between individual users were also obvious. We identified three groups of users based on their interaction. There were users that dealt with the tasks with little interaction (less than three moves). No users had any previous experience with $3 \mathrm{D}$ visualization. On the other hand, we identified a group of 5 people who scored average with respect to the interaction in most of the tasks. The remaining participants used variable 
sequences of individual movements. The number of participants in this study is too small, so results can not be generalized, but we want to further analyse individual differences during the interaction with $3 \mathrm{D}$ spatial data

Longer time intervals without an action were often detected at the beginning of the task performance. The data about actions in the interactive $3 \mathrm{D}$ visualization can be further analysed and visualized, e.g. as a trajectory above the stimuli (example shown in Fig. 8) or as a sequence of movements in a bar chart. Overall distances travelled by the participants in a virtual environment can be calculated.

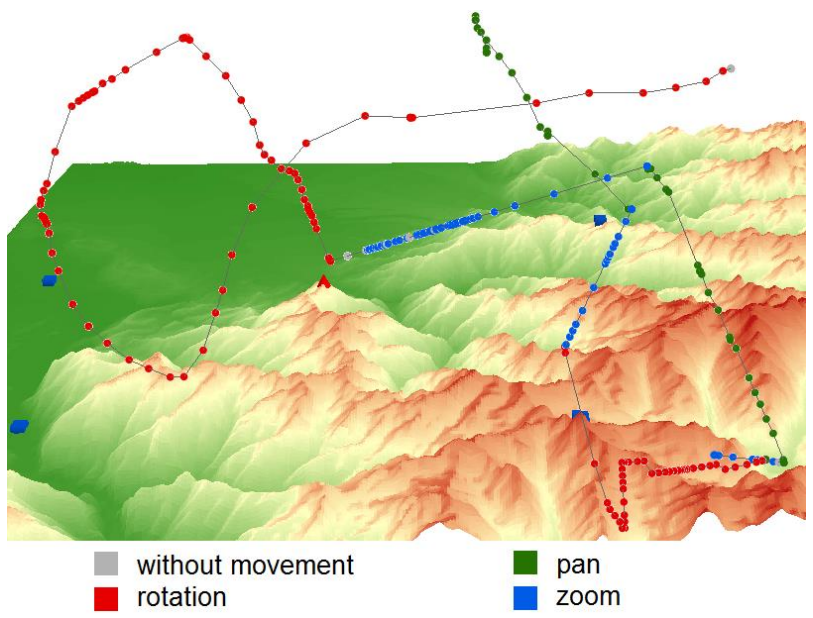

Fig. 8. Example of trajectory visualization

\section{DISSCUSION}

The presented results of a particular participant could be affected by participants' previous experience with 3D visualization. The analysis of data from the initial questionnaire shows that the participants working with static versions were more experienced and familiar with $3 \mathrm{D}$ visualization. In the future it will be useful to produce an initial questionnaire focused on these aspects and divide participants into groups according to the results of this questionnaire.

The differences in the results between the two types of visualization (static 3D vs. interactive 3D) are undoubtedly related to the concept of informational equivalence. Since the visualizations are informatively equivalent only if all information contained in one visualisation is derivable from the other one. For example this concept was published by Larkin and Simon (1987). We try to create informatively equivalent visualizations, when all key points necessary for the task performance were visible in both depictions of the terrain. Regarding the static visualization, a part of the terrain may be invisible since it may be hidden behind the terrain shape. The interactive visualization solves this issue. Therefore, a part of the information is hidden.

Larkin and Simon (1987) also describe a concept of computational equivalence. They assume that representations are computationally equivalent if a person is supposed to perform exactly the same number of psychological processes when reading them. In addition, the interactive $3 \mathrm{D}$ visualization need to take into account the process related to the control of $3 \mathrm{D}$ scene. The compared visualizations were not equivalent from this point of view. The higher cognitive load may cause an increase in the error rate or reduced user productivity in the following tasks.

\section{CONCLUSIONS AND FUTURE WORK}

The main aim of this study was to identify differences in user performance with static perspective views and interactive $3 \mathrm{D}$ visualizations. The study was carried out as exploratory research. In general, the participants working with static perspective views reached better results. They made fewer errors and were also faster. However, considerable differences occurred between participants in the both compared groups. Another type of errors the users made may suggest different approaches (strategies) during task performance.

In our opinion, the results of the static 3D experiments cannot be transferred to interactive GIS applications. We consider interactive $3 \mathrm{D}$ visualization as richer in terms of information and more computationally demanding on users, which is reflected in a higher error rate. Especially the more experienced users are able to cope with greater cognitive load. The interactive testing tool shall be used in order to make results relevant for interactive visualization. When comparing static perspective views with interactive $3 \mathrm{D}$ visualization, it seems to be better to use within-subject design of experiments. Based on the results of this study and previous similarly focused research (Sprinarova et al., 2015), we expect that interactive 3D visualization will be more useful for professionals (those with previous experience with $3 \mathrm{D}$ visualization), and for complex tasks in particular.

Due to considerable variability of correctness and duration of users' performances in particular (both in the static and in interactive variant), it will be necessary to focus on differences between different groups of users in the subsequent research. Regarding the interactive $3 \mathrm{D}$ visualization, it would be an interesting and challenging task not only to monitor correctness of answers and speed, but also user's strategies and cues used by the users for decision making For this purpose, it will be beneficial to use mixed research design, which combines advantages of quantitative and qualitative methods (Sterba et al., 2014; Popelka et al., 2016). Therefore, an extension tool 'Hypothesis module for interactive visualization' (described in detail in Sterba et al., 2015) is planned. This will allow to test 3D interactive visualization with eye-tracking (Brychtová et al., 2012). The research focused on 3D interactive visualization will also require a methodology to be developed (e.g. metrics for the movement in virtual space and interaction).

\section{ACKNOWLEDGEMENTS}

This research was funded by Grant No. MUNI/M/0846/2015, "Influence of cartographic visualization methods on the success of solving practical and educational spatial tasks" and Grant No. MUNI/A/1315/2015, "Integrated research on environmental changes in the landscape sphere of Earth", both awarded by Masaryk University, Czech Republic.

\section{REFERENCES}

Abend, P., Thielmann, T., Ewerth, R., Seiler, D., Mühling, M., Döring, J., Grauer, M., Freisleben, B. (2012) Geobrowsing behaviour in Google Earth - A semantic video content analysis 
of on-screen navigation. In Jekel T. A. et al. (eds.): GI_Forum 2012: Geovisualization, Society and Learning, pp. 2-13.

Behr, J., Eschler, P., Jung, Y., Zöllner, M. (2009). X3DOM - A DOM-based HTML5/ X3D Integration Model. In: Proceedings of Web3D 2009: The 14th International Conference on Web3D Technology, Web3D 2011, Darmstadt, Germany.

Bleisch, S., Dykes, J. (2008). Using Web-Based 3-D Visualization for Planning Hikes Virtually: An Evaluation. In: Mount NJ et al.: Representing, Modeling and Visualizing the Natural Environment: Innovations in GIS 13. Florida: CRC Press, pp. 353-365.

Bleisch, S., Dykes, J., Nebiker, S. (2008). Evaluating the Effectiveness of Representing Numeric Information Through Abstract Graphics in 3D Desktop Virtual Environments. Cartographic Journal. 45(3): 216-226.

Brychtova, A., Popelka, S., Vozenilek, V. (2012). The Analysis of Eye Movement as a Tool for Evaluation of Maps and Graphical Outputs from GIS. In Svobodová H. (ed.), Proceedings of the 19th International Conference on Geography and Geoinformatics: Challenge for Practise and Education. Brno, Czech Republic, pp. 154-162.

Haberling, C. (2003) Topografische 3D-Karten-Thesen für kartografische Gestaltungsgrundsätze. ETH Zürich.

Herman, L., Reznik, T. (2013). Web 3D Visualization of Noise Mapping for Extended INSPIRE Buildings Model. In: Hrebicek, J., Schimak, G., Kubasek, M., Rizzoli, A. E. (eds.) Environmental Software Systems. Fostering Information Sharing, Springer, pp. 414-424.

Herman, L., Reznik, T. (2015). 3D Web Visualization of Environmental Information - Integration of Heterogeneous Data Sources when Providing Navigation and Interaction. In Mallet C., et al. (eds.) ISPRS Archives of the Photogrammetry, Remote Sensing and Spatial Information Sciences, Vol. XL-3/W3. La Grande Motte, France, pp. 479-485.

Hirmas, D. R., Slocum, T., Halfen, A. F, White, T., Zautner, E., Atchley, P., Liu, H., Johnson, W. C., Egbert, S., McDermott, D. (2014). Effects of Seating Location and Stereoscopic Display on Learning Outcomes in an Introductory Physical Geography Class. Journal of Geoscience Education. 62(1): 126-137.

Jobst, M., Germanchis, T. (2007). The Employment of 3D in Cartography - An Overview. In: Cartwright, W., Peterson, M. P., Gartner, G. (eds.) Multimedia Cartography, Springer, pp. 217-228.

Konecny, M. (2011). Cartography: Challenges and Potentials in Virtual Geographic Environments Era. Annals of GIS. 17(3) Taylor \& Francis: 135-146.

Kovalcik, V., Chmelik, J., Bezdeka, M., Sochor, J. (2012). Virtual reality system as a tool for education. In: 20th International Conference in Central Europe on Computer Graphics, Visualization and Computer Vision, Plzen, Czech Republic, pp. 15-18.

Kraak, M. J. (1988) Computer-assisted cartographical threedimensional imaging techniques. Delft: Delft University Press.

Lin, H., Batty, M., Jørgensen, S., Fu, B., Konecny, M., Voinov, A., Torrens, P., Lu, G., Zhu, A., Wilson, J.P., Gong, J., Kolditz, O., Bandrova, T., Chen, M. (2015). Virtual Environments Begin to Embrace Process-based Geographic Analysis. Transactions In GIS, 19(4) Wiley: 493-498.
Larkin, J. H., Simon, H. A. (1987) Why a Diagram is (Sometimes) Worth Ten Thousand Words. Cognitive Science, 11(1): 65-100.

Niedomysl, T., Ellder, E., Larsson, A., Thelin, M., Jansund, B. (2013). Learning Benefits of Using 2D Versus 3D Maps: Evidence from a Randomized Controlled Experiment. Journal of Geography, 112(3) Taylor \& Francis: 87-96.

Petrovic, D., Masera, P. (2004) Analysis of User's Response on 3D Cartographic Presentations. In: Proceedings of the 7th meeting of the ICA Commission on Mountain Cartography, pp. $1-10$.

Popelka, S., Brychtova, A. (2013). Eye-tracking Study on Different Perception of 2D and 3D Terrain Visualization. Cartographic Journal. 50(3): 240-375. ISSN 0008-7041.

Popelka, S., Dolezelova, J. (2015). Non-photorealistic 3D Visualization in City Maps: An Eye-Tracking Study. In Brus J., Vondraková A., Voženílek V. (eds.) Modern Trends in Cartography. Springer: 357-367.

Popelka, S., Stachon, Z., Sasinka, C., Dolezelova, J. (2016). EyeTribe Tracker Data Accuracy Evaluation and Its Interconnection with Hypothesis Software for Cartographic Purposes. Computational Intelligence and Neuroscience. 2016. $14 \mathrm{p}$.

Rautenbach, V., Coetzee, S., Cöltekin, A. (2014) Towards evaluating the map literacy of planners in 2D maps and 3D models in South Africa. In: AfricaGEO 2014 Conference Proceedings.

Reznik, T., Horakova, B., Szturc, R. (2013). Geographic Information for Command and Control Systems Demonstration of Emergency Support System. In: Zlatanova, S., Dilo, A., Peters, R., Scholten, H. (eds.) Intelligent Systems for Crisis Management: Geo-information for Disaster Management (GI4DM) 2012, Springer, pp. 263-275.

Savage, D. M., Wiebe, E. N., Devine, H. A. (2004) Performance of 2D versus 3D Topographic Representations for Different task Types. In: Proceedings of the Human Factors and Ergonomics Society Annual Meeting, SAGE Publications, pp. 1793-1797.

Schobesberger, D., Patterson, T. (2007). Evaluating the Effectiveness of 2D vs. 3D Trailhead Maps. Mountain Mapping and Visualisation. In: Proceedings of the 6th ICA Mountain Cartography Workshop Mountain Mapping and Visualisation. pp. 201-205.

Shepherd, I. (2008). Travails in the Third Dimension: A Critical Evaluation of Three Dimensional Geographical Visualization. In: Dodge, M., McDerby, M., Turner, M. (eds.) Geographic Visualization: Concepts, Tools an Applications, Wiley, pp. 199222.

Stanek, K., Friedmannova, L., Kubicek, P., Konecny, M. (2010). Selected issues of cartographic communication optimization for emergency centers. International Journal of Digital Earth, 3(4): 310-339.

Sprinarova, K., Jurik, V., Sasinka, C., Herman, L., Sterba, Z., Stachon, Z., Chmelik, J., Kozliková, B. (2015). Humancomputer Interaction in Real 3D and Pseudo-3D Cartographic Visualization: A Comparative Study. In: Sluter, C. R., et al. (eds.) Cartography - Maps Connecting the World: 27th International Cartographic Conference 2015 - ICC2015. Springer, pp. 59-73. 
Sterba, Z., Sasinka, C., Stachon, Z., Kubicek, P., Tamm, S. (2014). Mixed Research Design in Cartography: A Combination of Qualitative and Quantitative Approaches. Kartographische Nachrichten. 64(5): 262-269.

Sterba, Z., Sasinka, C., Stachon, Z., Stampach, R., Morong, K., (2015). Selected Issues of Experimental testing in Cartography. Masaryk University, MuniPress, Brno.

Torres, J., Ten, M., Zarzoso, J., Salom, L., Gaitán, R., Lluch, J. (2013) Comparative Study of Stereoscopic Techniques Applied to a Virtual Globe. Cartographic Journal. 50(4): 369-375.

Vozenilek, V. (2005). Cartography for GIS: Geovisualization and Map Communication. 1st ed., Palacký University Olomouc, $142 \mathrm{p}$.

Wilkening, J., Fabrikant, S. I. (2013). How users interact with a 3D geo-browser under time pressure. Cartography and Geographic Information Science. 40(1) Taylor \& Francis: 4052.

X3DOM (2016). X3DOM - Documentation - Overview [online]. http://doc.x3dom.org (5. 4. 2016)

Zanola, S., Fabrikant, S. I., Coltekin, A. (2009). The Effect of Realism on the Confidence in Spatial Data Quality in Stereoscopic 3D Displays. In: Proceedings, 24th International Cartography Conference (ICC 2009), Santiago, Chile. 